\title{
Pharmacological and Toxicological assessment of common Plant poisons found in India
}

\author{
Sharanya Nath ${ }^{1}$ \\ ${ }^{1}$ Amity Institute of Forensic Sciences
}

July 27, 2021

\begin{abstract}
As far as prolepsis and treatment of diseases goes, recuperative plants are of specific significance in medication. The after effects of studies and research have indicated that some dynamic elements of recuperative plants are helpful for relief from discomfort and disease; research have additionally demonstrated that some therapeutic herbs have cell reinforcement and mitigating impacts in vitro. The utilization of domisticated medications has seen an extraordinary upsurge all around. In developed nations, many belittle them to a great extent because of social adequacy, accessibility and cost. Lately, be that as it may, there has been a continuous growing concern of usage of such medicinal plants. This has made a circumstance of vacillation in conversations with respect to their utilization. Some therapeutic plants are characteristically dangerous and toxic by virtue of their constituents and can cause antagonistic responses if improperly utilized. Different factors, for example, herb-medicated associations, absence of adherence to great assembling practice, poor administrative measures and contamination may likewise prompt to unhealthy and life threatening circumstances in their utilization. This article is a literature review of five most common medicinal plants which have equally toxic effects if used improperly.
\end{abstract}

\section{INTRODUCTION}

Plants since archaic times have been utilized for all intents and purpose, by all societies as a wellspring of medication. They are viewed as the foundation of customary medication and are generally used to treat intense and interminable illnesses. The World Health Organization evaluated that maybe $80 \%$ of the occupants of the world depend mainly on conventional prescriptions. The usage of medicinal plants is considered to be safe however, numerous hazardous and lethal symptoms have been accounted for too. These could be immediate poisonous impacts, unfavorably susceptible responses, allergic and toxic reactions, impacts from contaminants or potentially cooperations with drugs and different herbs.

Toxicology is essentially the study of toxins. A toxic substance is commonly viewed as any substance that can cause serious injury or demise because of a physicochemical cooperation and interaction with the living tissue. Nonetheless, all substances are potential toxins since every one of them can cause injury, adverse effects or in certain cases death after consumption in wrong dosage. There are three significant sites or destinations in the human body for the retention of toxins: the skin, lungs and gastrointestinal tract. The gastrointestinal tract is the most significant in toxicology as most remote mixes are ingested orally. Toxicological investigations help to choose whether another medication ought to be embraced for clinical use or not. Lethallity depends on the portion, usage and dosage of the substance as well as on the poisonous and toxic properties of the substance. The connection between these two elements is significant in the evaluation of restorative measurements in pharmacology and herbalism.

\section{DISCUSSION}

Ricinus Communis 


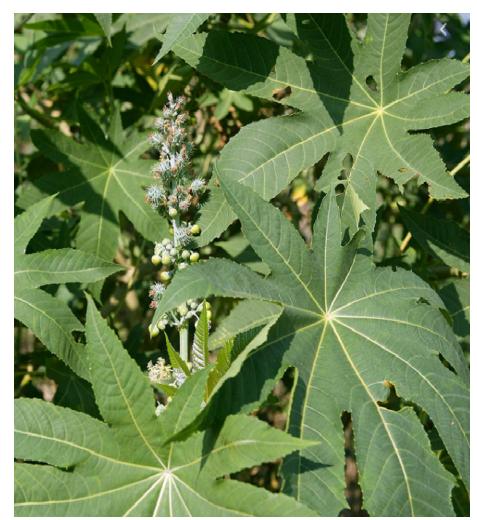

Fruit and leaf of Castor

\section{Pharmacological aspects:}

Ricinus communis Linn. is locally known as Castor or Arandi. It has a place with the family Euphorbiaceae. There are two kinds of seeds - an enormous red seed with darker blotches yielding around 40 percent of oil and a little dim seed having brilliant, cleaned, dark colored spots, yielding around 37 percent of oil, usually utilized for therapeutic reason.

The root area of this particular plant is utilised for great purposes, majorly it is used as an active ingredient of prescriptions for nervous aflictions and rheumatic diseases.

Not only this, but its aerial plant parts and parts of roots can also be used for treating diabetes.

The root, leaf and seed oil of this plant, according to the Indian system of medicine, has risen up to be very useful for curing maladies such as liver disorders and inflammation. This is proven as these parts of the plant have diuretic, hepatoprotective and laxative values.

\section{Toxicological aspects:}

The seeds of castor oil plant contain a functioning guideline called ricin. Ricin is a water solvent glycoprotein. It is a toxalbumin. Toxalbumin or phytotoxin is a harmful protein which causes agglutination of red platelets prompting haemolysis and cell pulverization. Its activity looks like bacterial poison. Toxalbumin goes about as an antigen when infused into body and antibodies are created. At the point when the oil of the castor seed is separated, the buildup is exceptionally toxic as it contains ricin. The castor oil seed isn't harmful whenever taken in that capacity, as pericarp of seeds isn't broken down by intestinal emissions and the seeds are dropped into stool. It is toxic when squashed seed is given.

A couple of hours after ingestion of the seeds, the gastrointestinal manifestations start. There is consuming agony in throat, sickness, spewing, thirst, and colicky torment in the belly. The runs with blood might be seen. Gradually, indications of drying out show up as weak heartbeat, low pulse, cold moist skin lastly demise because of stun. Oliguria might be seen.

The fatal dose is ten crushed seeds.

The fatal period is 1-2 days.

Croton tiglium 


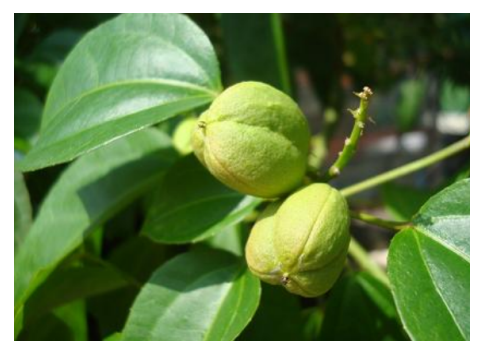

Fruit of Croton tiglium(Jayapala)

\section{Pharmacological aspects:}

It has a place with the family Euphorbiaceae and is broadly developed. The seeds, roots, leaves and the external bark are considered to be the medicinal parts of this plant.

Use of croton seed paste is significant for the treatment of alopecia by application over the scalp. Some people also use the same seed powder to cure constipation. This is because the dosage of $30-40 \mathrm{mg}$ of this powder acts as a purgation inducer thus, acts a colon cleanser.

In certain cases of snakebite, the Ayurveda suggests to use the paste of the croton seeds which is then mixed with a little lime juice and then can be utilised as collyrium.

Ayurveda physician use the paste of croton roots to treat diseases such as abscess, haemorrhoids and skin tags.

Jaundice can be cured using bark of croton root.

\section{Toxicological aspects:}

The seeds are extremely harmful. They contain crotin, a toxalbumin and crotonoside a glycoside.

The croton seed oil contains a ground-breaking vesicating gum made out of crotonoleic acid(corrosive), methyl crotonic acid(corrosive), crotonol and a few unsaturated fats. The croton oil has upsetting smell and acidic taste. At the point when it interacts with skin, it produces redness, tingling and rankles. At the point when taken inside by mouth, it produces disturbance of mucosa. Croton oil is a solid aggravating agent.

Promptly, once swallowed, there is extreme agony in throat, belly, heaving and looseness of the bowels which can turn lethal depending on the dosage. The cleansing is extremely serious. The individual may die in view of intense lack of hydration prompting hypovolaemic stun.

The fatal dose is one whole seed.

The fatal period is generally $12-24$ hours.

Abrus Precatorious






\section{Dual coloured seeds of Abrus precatorious}

\section{Pharmacological aspects:}

A. precatorius is a woody twinning plant with trademark poisonous red seeds with dark imprint at the base. Leaves look like tamarind leaves having 20-40 flyers. It is local to India, and is generally known as Ratti.

The seeds of Abrus prectorious is known to contain active ingredients which holds medical significance. These generally consist of chemical substances which can be highly toxic in nature if not handled properly; it includes anthocyanins, abrin and indole alkaloids. Although being extremely poisonous they are also used for medicinal purposes such as for contraceptives or as abortificants.

Also, according to ayurveda, A. Precatorious is a significant constituent in the medicine which is used to treat conjunctivitis.

The leaves of this plant contains glycirhizin, on using in required dosage it works as a expectorant and a soothing agent.

The roots contain tiny amounts of abrin which has antiallergic and anti-inflamatory properties.

\section{Toxicological aspects:}

The seeds of ratti contain abrin, a thermolabile toxalbumin. Its activities are like ricin. The seeds of ratti likewise contain hemaglutinin, fat spliting compound and some harmful proteins. Since abrin is thermolabile and it is inactivated by high temp water, the ratti seeds are innocuous on the off chance that they are bubbled appropriately.

The root and stem of ratti plant contains dynamic guideline of glycyrrhizin. In the event that concentrate of seeds is infused in the skin it produces aggravation and oedema prompting corruption around the site of infusion. Spasms might be there.

Ratti is broadly utilized as animal poison. The seeds might be squashed and blended in with dhatura, opium and onion to frame a glue, which is then made as needles which are then solidified in the sun. These needles are then put in a wooden handle. These are embedded into the various animals, particularly around genitalia, buttocks or vagina. In a couple of hours, irritation and oedema show up on the site. Later corruption of tissue may happen following death within 3-4 days. The side effects intently look like those of a snake bite.

The fatal dose is $90-120 \mathrm{mg}$.

The fatal period is $3-4$ days.

Claviceps purpurea

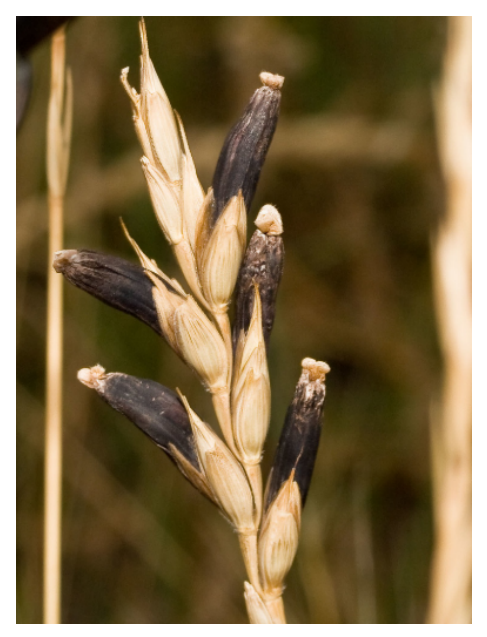




\section{Black coloured sclerotia of Ergot}

\section{Pharmacological aspects:}

Ergot is a parasitic growth that has a place with the variety Claviceps and structures known as sclerotia on different grasses and grains.

It belongs to a genus of fungi named Claviceps. It's sclerotia contains a chemical substance; ergotoxin which is an alkaloid and can help in restorative smooth muscle growth.

Hallucinogens in proper dosage can be used in therapeutic treatments, similarly the ergot derivatives are used as hallucinogens and thus show therapeutic properties.

The intramuscular organization of ergometrine(d-lysergic acid beta-propanolamide) derived from ergonovine is used to improve postpartum uterine constrictions.

\section{Toxicological aspects:}

Ergometrine produces impacts all the more quickly yet gangrene isn't usually observed.

Ergonovine maleate is a restorative arrangement derived from ergometrine and is an uterine constriction stimulant. Ergot is broadly utilized in the treatment of headache, albeit delayed use may create gangrene of lower appendages.

At first, there is dryness and irritation of throat, queasiness, regurgitating, consuming torment in stomach, looseness of the bowels, paraesthesia, unsettling influence of vision followed by feeble fast heartbeat, angina, trance like state and passing. Epistaxis, hematemis, haematuria may likewise be seen alongside jaundice.

The continuous after effects are found in people who continue taking ergot derivatives for therapeutic purposes for quite a while or in the individuals who continue eating grains pervaded with ergot growth. Introductory side effects are gastrointestinal. Before long, they are trailed by either convulsive or gangrenous structure. In convulsive structure, there are neurological manifestations like tingling, deadness, material pipedreams, paraesthesia, and agony while strolling. Before long, spasms start. In the gangrenous state, it begins with obscure torment in appendages, shivering sensation and later deadness of fingers and toes due to vasospasm.

The appendages become swollen and all sensations are no more

The fatal dose and fatal period; chronic toxicity causes death over a long period of consumption.

\section{Capsicum annum}

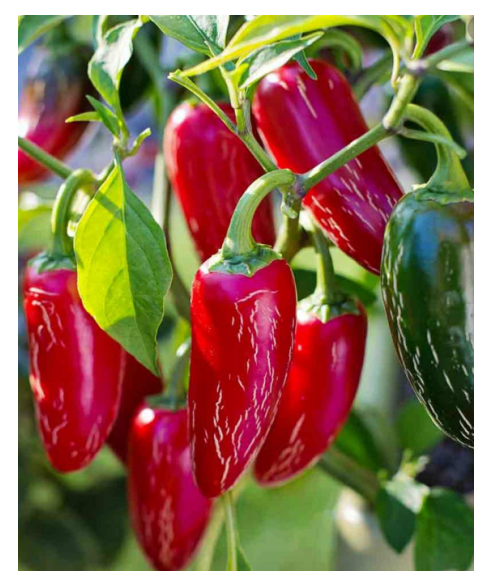

Typical and commonly seen fruit of Capsicum annum 


\section{Pharmacological aspects:}

Capsicum annuum Linn. having a place with the group of Solanaceae is generally grown in practically all the tropical nations.

Capsicum, genus capsicum and species annuum is a fruit which has been utilized orally for curing disturbed stomach and fever.

It is also known to have been used locally for pain relief in toothache. It also works in healing heat diseases and helps in poor circulation.

Capsicum can be utilized contemporarily to treat pains related to osteoarthritis and rheumatoid joint inflammation.

It also gives relief to fibromyalgia, and back pain related issues.

Capsaicin restrains corrosive emission of the stomach mucosa, invigorates soluble base and bodily fluid discharge and especially gastric mucosal flow of blood that further helps in anticipation and recuperating of gastric ulcers.

\section{Toxicological aspects:}

In enormous portions capsicum goes about as an aggravation poison. On consuming, it produces burning sensation in mouth and stomach. It causes extreme intense jabbing pain. The throat, stomach and small digestive system are inflamed and ulceration might be seen with burning diarrhea. Huge admission of chilies may cause peptic ulcer. If and when if powdered chillies is tossed into eyes, it causes redness, tingling and irritation of conjunctiva.

Chilies are likewise utilized in human suffering/torture. In such cases powder of Capsicum annum is placed in vagina, rectum, urethra, and eyes and scoured over bosoms. This induces high irritation of dermis and inflammation and redness follows and in severe cases neurotoxicity.

\section{COMPETING INTERESTS}

None.

\section{CONCLUSION}

Characteristic parts obtained from plants, have been the premise of treatment of infection in humans for generations. Around 500 plants with restorative use are referenced in old writings and around 800 plants have been utilized in indigenous frameworks of medication. India is an immense vault of restorative and medicinal plants that are utilized in customary clinical medicines.

For the most part, herbs contain bioactive mixture of compounds which show both intra-species and interspecies variety in type and substance. Plants by usage of their chemical/substance constituents are possibly dangerous; along these lines, a few plants utilized in customary medication are characteristically poisonous. Some of the plants notable in customary medication to be considered dangerous or toxic incorporate Atropa belladonna, Datura spp., Digitalis spp. Etc. These are also found in areas of India but not included in the article.

Numerous plants utilized in conventional medication or utilized as nourishment use have exhibited some poisonous and toxic quality (mutagenic and cancer-causing) impacts. Be that as it may, a portion of the poisonous plants are helpful to man as prescripted medicine and furthermore as toxic substances for use as pesticides. For instance, Datura (tropane alkaloids) and Pyrethrum (pyrethrin bug sprays).

\section{REFERENCES}

1. Kadambi, K. and S.N. Dabral. 1955. The silviculture of Ricinus communis Linn. Indian Forester 81(1): 53-58. 7 . 
2. Kang, S.S., Cordell, A., Soejarto, D.D., Fong, H.H.S., 1985. Alkaloids and flavonoids from Ricinus communis. J. Nat. Prod. 48 (1), 155-156. 8.

3. Darmanin S, Wismaver PS, Camillerri Podesta MT, Micallef MJ, Buhagiar JA. An extract from Ricinus communis L. leaves possesses cytotoxic properties and induces apoptosis in SKMEL- 28 human melanoma cells. Nat Prod Res 2009; 23(6): 561-571.

4. Chaudhary G, Goyal S, Poonia P. Lawsonia inermis Linnaeus: a phytopharmacological review. Int J Pharm Sci Drug Res. 2010;2(2):91-98.

5. Nadkarni KM. Indian materia medica Vol-I. Mumbai: Popular Prakashan; 1994. pp. 4-7.

6. Kirtikar KR, Basu BD. Indian medicinal plant Vol I. 2nd ed. Dehradun: International Book Distributors; 2005.

7. Prathyusha P, Subramanium MS, Sivakumar R. Pharmacognostical studies on white and red forms of Abrus precatorius Linn. Indian J Nat Prod Resour. 2010;1(4):476-480.

8. Attal AR, Otari KV, Shete RV, Upasani CD, Nandgude TD. Abrus precatorius Linnaeus: a phytopharmacological review. J Pharm Res. 2010;3(11):2585-2587.

9. Ross IA. Medicinal plants of the world: Volume 1 chemical constituents, traditional and modern medicinal uses. New York: Humana Press; 2003.

10. Gerhards N, Neubauer L, Tudzynski P, Shu-Ming Li. (2014). Biosynthetic Pathways of Ergot Alkaloids. Toxins. 6(12), 3281- 3295.

11. Ghali R, Léan JD, Douville Y, Noël HP. (1993). Raymond Labbé. Erythromycin-associated ergotamine. Annals of Vascular surgery. 7(3): 291-296.

12. Mulac D, Lepski S, Ebert F, Schwerdtle T, Humpf HU. (2013). Cytotoxicity and fl uorescence visualization of ergot alkaloids in human cell lines. J Agric Food Chem. 16;61(2): 462-71.

13. Sullivan R, Nelsen J, Duggineni S, Holland M. (2012). Management of methylergonovine induced respiratory. Informa healthcare Clinical Toxicology. 51(1): 47-49.

14. Ayushveda. Capsicum annuum [Internet] 2015 [cited on 2010 July 10]. Available from: http://www.ayushveda.com/herbs/capsicum-annuum.htm 5.

15. Kokate CK, Purohit AP, Gokhale SB. Pharmacognosy. 42nd edition. Pune: Nirali Prakashan; 2008. Chapter 11, Terpenoids, Capsicum annuum; 11.107-11.108. 6.

16. Kirtikar KR, Basu BD. Indian Medicinal Plants. 2nd Edition, 3rd Volume, Periodical Experts; 1975.Capsicum; 1769-1773 7.

17. MDidea Extracts Professional. Phytochemicals and Constituents of Capsicum:Cayenne,Red Pepper. [Internet] 2010 [cited on 15 July 2010]. available from: http://www.mdidea.com/products/new/new00504.html 